\title{
A lot to a little or a little to a lot-which dose-volume relationship ensures the best clinical outcome in the high dose radiation therapy of thoracic tumors? A prospective approach
}

\author{
Christina Schröder ${ }^{1,2}$, Rita Engenhart-Cabillic ${ }^{1}$, Hilke Vorwerk ${ }^{1}$, Michael Schmidt ${ }^{2}$, Winfried Huhnt ${ }^{2}$, \\ Eyck Blank ${ }^{2}$, Dietrich Sidow ${ }^{2}$, André Buchali ${ }^{2}$ \\ ${ }^{1}$ Clinic for Radiotherapy and Radiation Oncology, University Clinic Giessen and Marburg, Marburg, Germany; ${ }^{2}$ Clinic for Radiotherapy and \\ Radiation Oncology, Ruppiner Kliniken GmbH, Neuruppin, Germany \\ Contributions: (I) Conception and design: C Schröder, A Buchali, R Engenhart-Cabillic; (II) Administrative support: A Buchali, R Engenhart-Cabillic; \\ (III) Provision of study materials or patients: A Buchali, E Blank, D Sidow, M Schmidt, W Huhnt; (IV) Collection and assembly of data: C Schröder, \\ A Buchali; (V) Data analysis and interpretation: C Schröder, H Vowerk; (VI) Manuscript writing: All authors; (VII) Final approval of manuscript: All \\ authors. \\ Correspondence to: Christina Schröder. Clinic for Radiotherapy and Radiation Oncology, University Clinic Giessen and Marburg, 35043 Marburg, \\ Germany. Email: christina.schroeder@med.uni-giessen.de.
}

Background: The purpose of this prospective randomized trial is to determine which constellation of dose and corresponding volume of the lung tissue-either a lot to a little or a little to a lot—should be preferred to ensure the best possible outcome for patients with thoracic carcinomas.

Methods: From Apr 2012 to Oct 2015, 81 patients with NSCLC, SCLC or esophageal carcinoma were randomized and treated with either a 4-field-IMRT or a VMAT technique with or without additional chemotherapy. Data regarding clinical outcome, pulmonary function tests (PFT) and quality of life (QoL) was collected before RT, 6 weeks, 12 weeks and 6 months after treatment, QoL data additionally 1 year post RT. Follow up CTs were done 12 weeks and 6 months after RT.

Results: There is no significant difference regarding the local $(\mathrm{P}=0.954)$ and distant $(\mathrm{P}=0.206)$ outcome, side effects (all $\mathrm{P}>0.05)$ or survival $(\mathrm{P}=0.633)$ at any follow-up appointment. The comparison of the PFT shows a statistically significant difference for the DLCO 6 weeks post RT $(\mathrm{P}=0.028)$. All other parameters do not differ significantly at any follow up appointment. Regarding the QoL there is no statistically significant difference at any follow up appointment $(\mathrm{P}>0.1)$. There is a statistically significant difference between the mean density of the lung parenchyma at 12 weeks $(\mathrm{P}<0.0005)$ and 6 months post $\mathrm{RT}(\mathrm{P}<0.0005)$.

Conclusions: Since there is no significant and relevant difference between both treatment arms regarding PFT, clinical outcome and QoL it does not seem to relevant how the DVH is shaped exactly as long as established dose constraints for the organs at risk are respected. As to whether the difference between the CT density changes is clinically relevant further analysis is needed.

Keywords: Lung neoplasms; respiratory function tests; radiation pneumonitis (RP); intensity modulated radiotherapy (IMRT); quality of life (QoL)

Submitted May 27, 2016. Accepted for publication Jun 10, 2016.

doi: $10.21037 /$ jtd.2016.07.92

View this article at: http://dx.doi.org/10.21037/jtd.2016.07.92 


\section{Introduction}

The intensity modulated radiotherapy (IMRT) is one of the most important technical developments in radiation treatment in the last decades. It allows delivering a high radiation dose with a great conformity and precision. Due to the inverse planning algorithm there are few restrictions regarding radiation field numbers, sizes and beam angles. This opens up the question what constellation of treatment fields should be preferred to ensure the best possible outcome for the patient. There are widely accepted dose constraints based on critical values regarding severe treatment related side effects (1-10). This includes the limitation of mean dose $(1,3,5-8,10,11)$ or constraints regarding the dose-volume relationship for organs at risk $(1-9,11)$. However, within these dose constraints there are numerous ways to shape a dose volume histogram (DVH). Generally, with the introduction of IMRT and further treatment techniques like volumetric modulated irradiation $\left[\right.$ VMAT, rapid $\left.\operatorname{arc}^{\circledast}(\mathrm{RA})\right]$ the number of treatment angles seems to increase, resulting in a larger volume that receives a low dose ("a little to a lot"). Contrary to this, a reduction of treatment angles leads to a smaller volume receiving a large radiation dose ("a lot to a little"). This especially applies to organs at risk that are both large in volume themselves and largely irradiated in the treatment surrounded tumors, as for example the lung. The question exactly which constellation should be preferred - "A lot to a little or a little to a lot?"has only been the subject of very few studies in the past. They usually only dealt with certain aspects like treatment-induced toxicities and the results are inconclusive. Willner et al. published the results of an analysis of the correlation between clinical and DVH data (12). They stated that "a lot to a little" should be preferred in order to reduce the volume receiving more than $40 \mathrm{~Gy}$, which seems to greater reduction of radiation pneumonitis (RP) than the corresponding reduction in the low dose areas. Later there was a critical review on RP and pulmonary fibrosis by $\mathrm{V}$. Mehta who concluded that a lot to a little is only safe up to a dose of $10 \mathrm{~Gy}(6)$.

In this study we wanted to take a wider approach to answer the underlying question. So we have performed a prospective randomized trial focusing on objective and subjective parameters like clinical outcome, changes in pulmonary function tests (PFT), radiological changes and quality of life (QoL).

\section{Methods}

\section{Patient characteristics}

Eligible for the trial were curatively treatable patients with intrathoracical carcinoma (NSCLC, SCLC, esophageal carcinoma) with a written consent of participation and a Karnofsky index (KI) of at least $70 \%$. Exclusion criteria were a lung operation in the patient's medical history, a relevant pleural effusion visible in the planning $\mathrm{CT}$, a forced expiratory volume in 1 second $\left(\mathrm{FEV}_{1}\right)$ of less than $1 \mathrm{~L}$, the refusal of participation and a KI of less than $70 \%$. The patients were randomly assigned to the treatment groups according to their total treatment dose, gender, concurrent chemotherapy, diabetes mellitus (if medically treated), arterial hypertension (if medically treated) and pretherapeutic lung function.

From April 2012 to October 2015, 96 patients were primarily included of which 15 had to be excluded during the treatment planning process due to violation of dose constraints $(n=6)$, acute reasons during the treatment planning process $(n=5)$, withdrawal of the consent of participation $(n=2)$ or others $(n=2)$. In total 81 patients were randomized and accepted to the study protocol. NSCLC patients were treated with a total radiation dose of 74 Gy, SCLC patients with 60 Gy and patients with esophageal carcinoma with 66 Gy. Fraction dose was 2 Gy each. Eligible patients received chemotherapy according to intradepartmental standards.

During concurrent RCT patients with NSCLC received cisplatin $\left(80 \mathrm{mg} / \mathrm{m}^{2}\right)$ and vinorelbine $\left(15 \mathrm{mg} / \mathrm{m}^{2}\right)$. Patients with SCLC received cisplatin $\left(75 \mathrm{mg} / \mathrm{m}^{2}\right)$ and etoposide $\left(120 \mathrm{mg} / \mathrm{m}^{2}\right)$ simultaneously. Patients with esophageal carcinomas were treated with cisplatin $\left(75 \mathrm{mg} / \mathrm{m}^{2}\right)$ and 5-Fluoruracil (5 FU) $\left(800 \mathrm{mg} / \mathrm{m}^{2} / 24 \mathrm{~h}\right)$. If the glomerular filtration rate was lower than $60 \mathrm{~mL} / \mathrm{min}$ patients received Carboplatin AUC 5 instead of Cisplatin. The median age of patients was 66 years. Most patients had NSCLC $(n=35)$ or esophageal cancer $(n=35)$, followed by SCLC $(n=11)$. All patients completed the treatment protocol.

Further patient characteristics are shown in Table 1.

\section{Treatment arms}

In both treatment arms established radiation treatment planning strategies were used. In treatment arm A, patients received a 4-field-IMRT treatment plan which was delivered in "sliding window" technique, resulting in the irradiation of a lower volume with a greater dose ("a lot to a little"). For treatment arm B volumetric modulated radiation treatment in "rapid arc"TM (Varian medical Systems) technique was used (at least one arc), resulting in the irradiation of a greater volume with a lower dose ("a little to a lot"). The 
Table 1 Patient characteristics

\begin{tabular}{|c|c|c|c|c|}
\hline \multirow{2}{*}{ Variables } & \multicolumn{2}{|c|}{ Treatment arm } & \multirow{2}{*}{ Total $(n=81)$} & \multirow{2}{*}{$P$ value } \\
\hline & $A(n=43)$ & $B(n=38)$ & & \\
\hline Sex & & & & 0.782 \\
\hline Female & 8 & 8 & 16 & \\
\hline Diabetes & & & & 0.983 \\
\hline Hypertension & & & & 0.843 \\
\hline Not present & 11 & 9 & 20 & \\
\hline Present & 32 & 29 & 61 & \\
\hline PFT & & & & 0.244 \\
\hline No & 12 & 11 & 23 & \\
\hline Yes & 31 & 27 & 58 & \\
\hline Entity (total radiation dose) & & & & 0.671 \\
\hline SCLC (60 Gy) & 7 & 4 & 11 & \\
\hline Esophageal carcinoma (66 Gy) & 17 & 18 & 35 & \\
\hline NSCLC (74 Gy) & 19 & 16 & 35 & \\
\hline Smoking history & & & & 0.654 \\
\hline Never & 4 & 2 & 6 & \\
\hline Present & 19 & 20 & 39 & \\
\hline UICC stage* (esophageal carcinoma) & & & & 0.498 \\
\hline $\mathrm{IA} / \mathrm{IB}$ & 1 & 1 & 2 & \\
\hline IIB & 3 & 1 & 4 & \\
\hline IIIA & 7 & 11 & 18 & \\
\hline IIIB & 1 & 1 & 2 & \\
\hline IIIC & 0 & 1 & 1 & \\
\hline IV & 5 & 3 & 8 & \\
\hline
\end{tabular}

*, Pearson's Chi-Square-Test.

treatment plans were calculated by a medical physicist using Eclipse software ${ }^{\mathrm{TM}}$ (Varian medical Systems) with an AAA algorithm for dose calculation. The physicist calculated both the IMRT and the RA plan not knowing to which plan the patient has been randomly assigned to.
All treatment plans had to match intradepartmental dose constraints and were identically standardized using the PTV. Dose constraints for the lung were V20 Gy $<30 \%$, V30 Gy $<20$ Gy and V20 Gy $<1,000 \mathrm{~mL}$; for the spinal cord a maximum dose $\left(D_{\max }\right)<47$ Gy; for the esophagus a $D_{\max }$ 


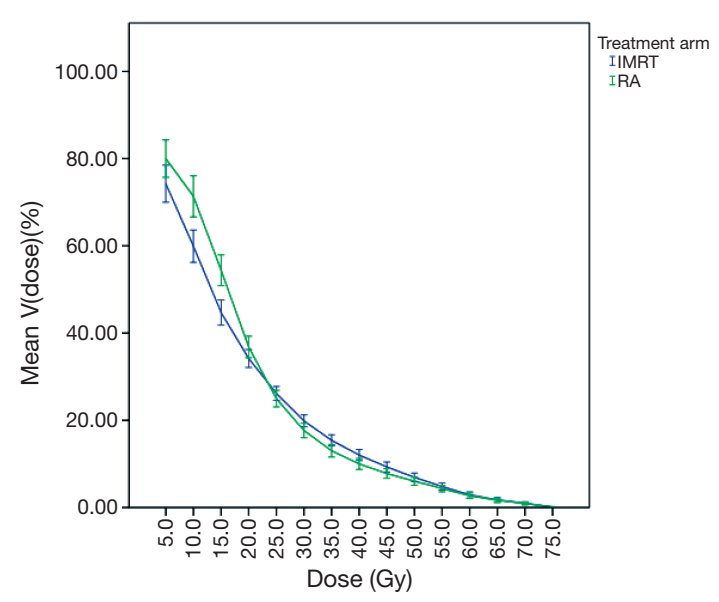

Figure 1 Comparison of dose-volume parameters of the lung (with $95 \% \mathrm{CI})$.

$<74$ Gy and for the heart a mean dose <35 Gy, D $33 \%<60$ Gy und $\mathrm{D}_{50 \%}<45 \mathrm{~Gy}$. All these dose values refer to biological doses. If one of the patients treatment plans was violating these constraints, the patient was excluded from the study.

\section{Study protocol}

The main aspect of this study was the comparison of the lung function, clinical outcome (survival, distant and local control, toxicity) and QoL of patients in the two treatment arms. Additional analyses were performed regarding the radiological changes in lung tissue after RT and the comparison of each patient's IMRT and RA plan to analyze the impact of the number of treatment angles on the DVH. During the course of the study each patient should have attended five appointments at which data were collected. These appointments were before radiation treatment, 6 weeks, 12 weeks, 6 months and 12 months after RT. Data of patients that were not able to attend all appointments was also used for analysis.

For the analysis of the QoL two standardized questionnaires were used; the EORTC QLQ-C30 and the EORTC QLQ-LC13 $(13,14)$. QoL data were collected at all five appointments.

As for lung function the following parameters were analyzed: vital capacity (VC), total lung capacity (TLC), $\mathrm{FEV}_{1}$, diffusion capacity for carbon monoxide (DLCO) and blood gas analysis. Lung function data was collected before RT, 6 weeks, 12 weeks und 6 month after RT. Clinical data regarding distant and local control, toxicity and survival were collected at all five appointments. For the analysis of radiological changes, the treatment planning CT and the restaging CTs 12 weeks and 6 months after RT were used. The CT analysis mainly focused on lung density changes after RT.

\section{Statistical analysis}

For the comparison of treatment plans a Wilcoxon test for paired samples was used. The lung function was analyzed using U-Test for the comparison of the treatment arms. For the comparison of the QoL data was transformed to two overall values according to (15). These QoL values where compared using the U-Test. For the clinical outcome Chi-Square test was used and for the radiological changes the $t$-test. Regarding survival Kaplan Meier curves where generated and compared using the Log-Rank test. For statistical analysis, SPSS version 22 was used.

\section{Statement of ethics approval}

We received an approval by the ethics committee of the state chamber of physicians of Brandenburg ("Landesärztekammer Brandenburg") on 05/03/2012 [reference S 10(a)/2012]. Additionally every patient had to give a written consent of participation before being included into the study.

\section{Results}

\section{Comparison of the DVH of the IMRT and RA treatment plans}

The dose-volume relations of the lung were compared in 5 Gy steps. The mean irradiated volume differed statistically significant for nearly all dose values with the mean volume being greater at lower doses for rapid arc plans and greater at higher doses for IMRT plans. Only at 25 Gy the values did not differ significantly which is not surprising considering that both curves intersect at 23.4 Gy. Figure 1 shows the dose-volume curves of the lung for both treatment arms. As for the other thoracic OAR like heart and esophagus the DVH differed significantly for the mean heart dose and the D33\% (both bigger for IMRT), but not for the D50\% and maximum dose of the esophagus.

\section{Comparison of lung function parameters}

The comparison of lung function tests showed a statistically significant difference between the treatment arms for the 
Table 2 PFT values post RT, median values (median \% of pre-treatment values) with associated $\mathrm{P}$ values

\begin{tabular}{|c|c|c|c|c|c|c|c|c|c|}
\hline & \multicolumn{3}{|c|}{6 weeks post RT } & \multicolumn{3}{|c|}{12 weeks post RT } & \multicolumn{3}{|c|}{6 months post RT } \\
\hline & A & $\mathrm{B}$ & $\mathrm{P}$ & A & B & $\mathrm{P}$ & A & B & $\mathrm{P}$ \\
\hline $\mathrm{FEV}_{1}(\%)$ & $1.96(97.1)$ & $2.01(98.8)$ & 0.994 & $1.71(94.7)$ & $1.81(97.1)$ & 0.799 & $1.51(89.7)$ & $1.73(91.7)$ & 0.377 \\
\hline TLC (\%) & $5.68(95.2)$ & $6.05(97.1)$ & 0.804 & $5.73(92.9)$ & $6.01(93.1)$ & 0.445 & $5.16(86.3)$ & $5.92(92.5)$ & 0.782 \\
\hline $\mathrm{DLCO}(\mathrm{mmol} / \mathrm{min} / \mathrm{kPa})(\%)$ & $3.83(86.1)$ & $3.54(74.5)$ & $0.028^{*}$ & $3.80(80.8)$ & $3.91(79.0)$ & 0.945 & $3.99(80.1)$ & $3.91(76.0)$ & 0.665 \\
\hline $\mathrm{pO}_{2}(\mathrm{mmHg})(\%)$ & $59.7(104.0)$ & $60.4(96.6)$ & 0.336 & $65.7(96.3)$ & $62.0(95.5)$ & 0.523 & $59.3(95.8)$ & $59.9(97.0)$ & 0.473 \\
\hline
\end{tabular}

*, $\mathrm{P}<0.05$.

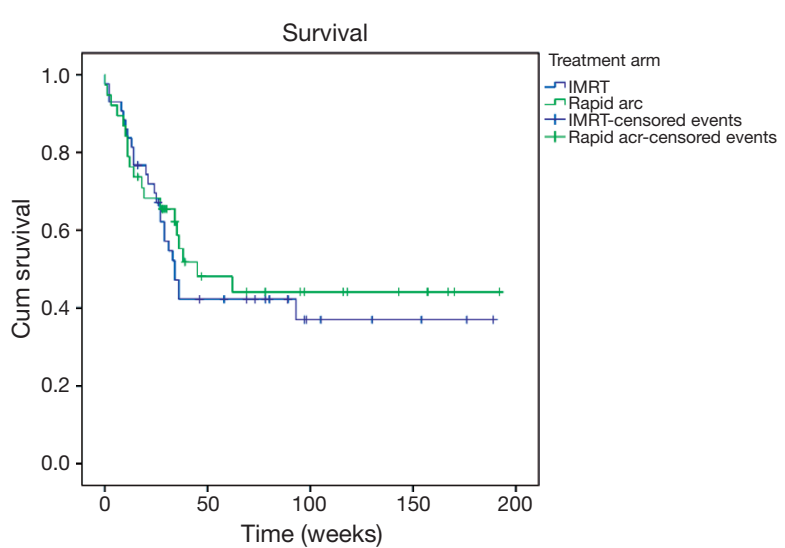

Figure 2 Comparison of overall survival of patients $(n=81)$.

DLCO 6 weeks post treatment with the decline in DLCO being greater in the RA arm. All other parameters did not differ significantly at any follow up appointment. Table 2 shows the results of the U-tests.

\section{Comparison of QoL}

Regarding the QoL there was no statistically significant difference between the summarized value for the QLQ-C30 and the QLQ-LC13 at any follow up appointment $(\mathrm{P}>0.1)$. Also there was no significant change of the $\mathrm{QoL}$ values over the course of the trial $(\mathrm{P}=0.418$ for QLQ-C30 and $\mathrm{P}=0.387$ for QLQ-LC).

\section{Comparison of clinical outcome and survival}

The mean follow up was 52 weeks. There was no significant difference regarding the local and distant outcome of patients in the two treatment arms at any follow up appointment $(\mathrm{P}=0.954$ and $\mathrm{P}=0.206)$. Overall there were only a few severe side effects (up to $9 \%$ ). Up to $15 \%$ of patients with preexisting dysphagia even experienced improvement. Regarding RT induced side effects there were no significant differences between the treatment arms. There is a difference in the time course of the RT induced toxicities. The prevalence of dysphagia peaked at the end of RT and 6 weeks after RT whereas RP peaked later at 12 weeks after treatment.

The median survival time was 36 weeks. At the time of analysis 37 patients were still alive. There was no statistically significant difference in survival between the treatment arms $(\mathrm{P}=0.633)$. Figure 2 shows the Kaplan-Meier curve.

\section{Comparison of radiological changes}

There was a statistically significant difference between the mean density of the lung parenchyma at 12 weeks $(\mathrm{P}<0.0005)$ and 6 months $(\mathrm{P}<0.0005)$ post $\mathrm{RT}$. The mean density change at 12 weeks was $142.0 \mathrm{HU}$ for IMRT and $70.7 \mathrm{HU}$ for RA patients. At 6 months these values were $106.3 \mathrm{HU}$ for IMRT patients and $60.9 \mathrm{HU}$ for RA patients. Figure 3 shows the mean changes in lung density for both treatment arms at 12 weeks and 6 months after treatment.

\section{Discussion}

No difference was found between patients treated with 4-field IMRT (a lot to a little) or RA (a little to a lot) regarding lung function, QoL and clinical outcome during the time of the trail.

The comparison of the DVH of patients proves though that there is a statistically significant difference of the dose distribution between the treatment arms for each patient. So it can be stated that there is at least a significant mathematical difference between both treatment arms. 


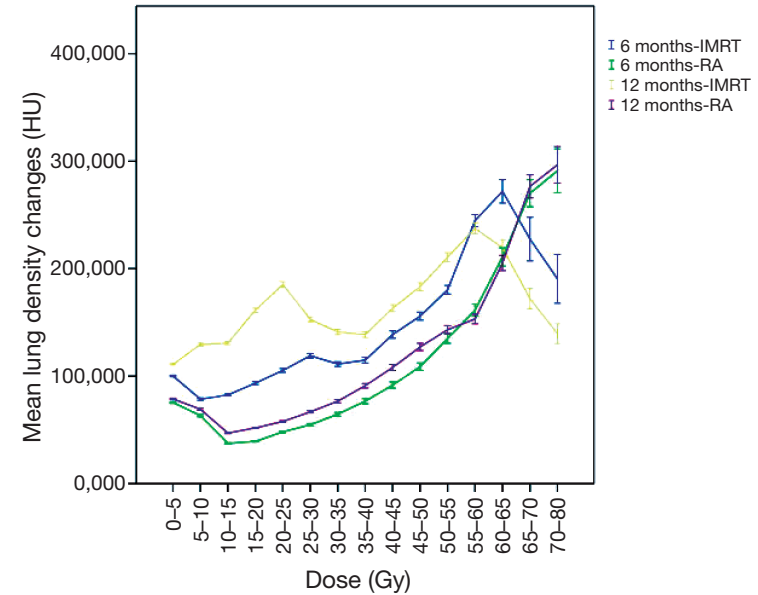

Figure 3 Comparison of lung density changes in the follow-up CT Scans 12 weeks and 6 months after RT (with $95 \%$ CI).

The only significant difference in lung function after treatment was found for the DLCO 6 weeks post RT which is interesting since the DLCO is the only parameter that decreases in almost every patient and changes statistically significant over time. This has also been stated in previous studies (16-26). Ventilation parameters on the other hand show a larger variety, possibly due to the re-opening of atelectasis $(20,23)$. It is interesting though that the difference in DLCO is only significant at 6 weeks post RT and no longer at 12 weeks or 6 months. This might be due to the fact that in total a larger volume is irradiated when using RA. With the DLCO values at 6 weeks for RA having a larger decline than those for IMRT one could argue that the total irradiated lung volume including the low dose areas has an influence on possibly partially transient early lung tissue injuries.

Some previously published results indicate that post treatment lung function is depending on certain dose parameters, but that usually refers to specific values like the mean lung dose and V20 Gy $(20,27)$. There is no information as to the shape of the DVH within those. So it might not be surprising that there is only one significant difference between the treatment arms since all treatment plans in this trial had to fulfill the same dose requirements regarding V20 Gy, V30 Gy and the mean lung dose.

Also the results regarding QoL are not surprising. Although one of the most important parameters for the patient it strongly depends on factors like symptom burden and treatment related side effects, which show no significant difference between the groups themselves $(28,29)$. Also because it is subjective there are great interindividual and intraindividual differences, which might explain the fact that there are no statistically significant changes of the QoL during course of the trial according to the GLM.

Perhaps more importantly there was also no difference in clinical outcome, side effects or survival. Generally only a few patients experienced severe side effects during or after treatment. For the prevention of RP or dysphagia there are well-established dose constraints that had to be matched during treatment planning $(6,8)$. If patients did not match those they were excluded from the investigation. Therefore it is not surprising that the overall toxicity burden was low (30) and did not differ between the treatment groups.

Also regarding survival no difference between the treatment arms could be found. The overall survival in this cohort is probably most dependant on entity, which did not differ between the treatment arms.

The analysis of the CT scans post RT reveals that there is a statistically significant difference between the treatment arms. Further analysis of this data is needed though to evaluate on how CT density changes translate into clinically relevant correlates like RT induced lung tissue damage and PFT changes. Early density changes are an indicator for RP and can be visible even though there are no clinical symptoms. Changes in density as a result of fibrosis are likely to occur later after treatment, being that fibrosis is usually a late RT induced toxicity.

Also there seems to be a correlation between CT density changes and PFT changes which mainly affects the decline of the DLCO, most likely because both parameters are an indicator for local tissue damage.

\section{Conclusions}

Since there is no significant and relevant difference between both treatment arms regarding PFT, clinical outcome and QLQ it doesn't seem to be relevant how the DVH is shaped exactly as long as certain established dose constraints are respected. As to whether the difference between the CT density changes is not only significant but also clinically relevant further analysis is needed.

\section{Acknowledgements}

None.

\section{Footnote}

Conflicts of Interest: The authors have no conflicts of interest to declare. 
Ethical Statement: We received an approval by the ethics committee of the state chamber of physicians of Brandenburg ("Landesärztekammer Brandenburg") on 05/03/2012 [reference S 10(a)/2012]. Additionally every patient had to give a written consent of participation before being included into the study.

\section{References}

1. Leprieur EG, Fernandez D, Chatellier G, et al. Acute radiation pneumonitis after conformational radiotherapy for nonsmall cell lung cancer: clinical, dosimetric, and associated-treatment risk factors. J Cancer Res Ther 2013;9:447-51.

2. Roeder F, Friedrich J, Timke C, et al. Korrelation von patientenbezogenen Faktoren und Dosis-VolumenHistogramm-Parametern mit dem Auftreten einer radiogenen Pneumonitis bei Patienten mit kleinzelligem Bronchialkarzinom. Strahlenther Onkol 2010;186:149-56.

3. Kong FM, Hayman JA, Griffith KA, et al. Final toxicity results of a radiation-dose escalation study in patients with non-small-cell lung cancer (NSCLC): predictors for radiation pneumonitis and fibrosis. Int J Radiat Oncol Biol Phys 2006;65:1075-86.

4. Rancati T, Ceresoli GL, Gagliardi G, et al. Factors predicting radiation pneumonitis in lung cancer patients: a retrospective study. Radiother Oncol 2003;67:275-83.

5. Hernando ML, Marks LB, Bentel GC, et al. Radiationinduced pulmonary toxicity: a dose-volume histogram analysis in 201 patients with lung cancer. Int J Radiat Oncol Biol Phys 2001;51:650-9.

6. Mehta V. Radiation pneumonitis and pulmonary fibrosis in non-small-cell lung cancer: pulmonary function, prediction, and prevention. Int J Radiat Oncol Biol Phys 2005;63:5-24.

7. Graham MV, Purdy JA, Emami B, et al. Clinical dosevolume histogram analysis for pneumonitis after $3 \mathrm{D}$ treatment for non-small cell lung cancer (NSCLC). Int J Radiat Oncol Biol Phys 1999;45:323-9.

8. Abratt RP, Morgan GW. Lung toxicity following chest irradiation in patients with lung cancer. Lung Cancer 2002;35:103-9.

9. Chen C, Uyterlinde W, Sonke JJ, et al. Severe late esophagus toxicity in NSCLC patients treated with IMRT and concurrent chemotherapy. Radiother Oncol 2013;108:337-41.

10. De Ruysscher D, Van Meerbeeck J, Vandecasteele K, et al. Radiation-induced oesophagitis in lung cancer patients. Is susceptibility for neutropenia a risk factor? Strahlenther Onkol 2012;188:564-7.

11. Barriger RB, Forquer JA, Brabham JG, et al. A dosevolume analysis of radiation pneumonitis in nonsmall cell lung cancer patients treated with stereotactic body radiation therapy. Int J Radiat Oncol Biol Phys 2012;82:457-62.

12. Willner J, Jost A, Baier K, et al. A little to a lot or a lot to a little? An analysis of pneumonitis risk from dosevolume histogram parameters of the lung in patients with lung cancer treated with 3-D conformal radiotherapy. Strahlenther Onkol 2003;179:548-56.

13. Bergman B, Aaronson NK, Ahmedzai S, et al. The EORTC QLQ-LC13: a modular supplement to the EORTC Core Quality of Life Questionnaire (QLQ-C30) for use in lung cancer clinical trials. EORTC Study Group on Quality of Life. Eur J Cancer 1994;30A:635-42.

14. Aaronson NK, Ahmedzai S, Bergman B, et al. The European Organization for Research and Treatment of Cancer QLQ-C30: a quality-of-life instrument for use in international clinical trials in oncology. J Natl Cancer Inst 1993;85:365-76.

15. Jurke F. Veränderung der Lebensqualität bei Patienten mit Prostatakarzinom nach endoskopischer extraperitonealer radikaler Prostatektomie (EERPE). Available online: http://www.diss.fu-berlin.de/diss/servlets/ MCRFileNodeServlet/FUDISS_derivate_000000013685/ diss_f.jurke.pdf

16. Krengli M, Sacco M, Loi G, et al. Pulmonary changes after radiotherapy for conservative treatment of breast cancer: a prospective study. Int J Radiat Oncol Biol Phys 2008;70:1460-7.

17. Jaén J, Vázquez G, Alonso E, et al. Long-term changes in pulmonary function after incidental lung irradiation for breast cancer: a prospective study with 7-year follow-up. Int J Radiat Oncol Biol Phys 2012;84:e565-70.

18. Jaén J, Vázquez G, Alonso E, et al. Changes in pulmonary function after incidental lung irradiation for breast cancer: A prospective study. Int J Radiat Oncol Biol Phys 2006;65:1381-8.

19. Erven K, Weltens C, Nackaerts K, et al. Changes in pulmonary function up to 10 years after locoregional breast irradiation. Int J Radiat Oncol Biol Phys 2012;82:701-7.

20. Lopez Guerra JL, Gomez DR, Zhuang Y, et al. Changes in pulmonary function after three-dimensional conformal radiotherapy, intensity-modulated radiotherapy, or proton beam therapy for non-small-cell lung cancer. Int $\mathrm{J}$ Radiat Oncol Biol Phys 2012;83:e537-43. 
21. Borst GR, De Jaeger K, Belderbos JS, et al. Pulmonary function changes after radiotherapy in non-small-cell lung cancer patients with long-term disease-free survival. Int J Radiat Oncol Biol Phys 2005;62:639-44.

22. Gopal R, Starkschall G, Tucker SL, et al. Effects of radiotherapy and chemotherapy on lung function in patients with non-small-cell lung cancer. Int $J$ Radiat Oncol Biol Phys 2003;56:114-20.

23. De Jaeger K, Seppenwoolde Y, Boersma LJ, et al. Pulmonary function following high-dose radiotherapy of non-small-cell lung cancer. Int J Radiat Oncol Biol Phys 2003;55:1331-40.

24. Abratt RP, Willcox PA. The effect of irradiation on lung function and perfusion in patients with lung cancer. Int $\mathrm{J}$ Radiat Oncol Biol Phys 1995;31:915-9.

25. Stanic S, Paulus R, Timmerman RD, et al. No clinically significant changes in pulmonary function following stereotactic body radiation therapy for early- stage peripheral non-small cell lung cancer: an analysis of RTOG 0236. Int J Radiat Oncol Biol Phys 2014;88:1092-9.

26. Guckenberger M, Klement RJ, Kestin LL, et al. Lack of

Cite this article as: Schröder C, Engenhart-Cabillic R, Vorwerk H, Schmidt M, Huhnt W, Blank E, Sidow D, Buchali A. A lot to a little or a little to a lot-which dose-volume relationship ensures the best clinical outcome in the high dose radiation therapy of thoracic tumors? A prospective approach. J Thorac Dis 2016;8(8):2053-2060. doi: 10.21037/jtd.2016.07.92 a dose-effect relationship for pulmonary function changes after stereotactic body radiation therapy for early-stage non-small cell lung cancer. Int J Radiat Oncol Biol Phys 2013;85:1074-81.

27. Theuws JC, Kwa SL, Wagenaar AC, et al. Prediction of overall pulmonary function loss in relation to the 3-D dose distribution for patients with breast cancer and malignant lymphoma. Radiother Oncol 1998;49:233-43.

28. Hallqvist A, Bergman B, Nyman J. Health related quality of life in locally advanced NSCLC treated with high dose radiotherapy and concurrent chemotherapy or cetuximab-pooled results from two prospective clinical trials. Radiother Oncol 2012;104:39-44.

29. Mohan A, Singh P, Singh S, et al. Quality of life in lung cancer patients: impact of baseline clinical profile and respiratory status. Eur J Cancer Care (Engl) 2007;16:268-76.

30. Schröder C, Blank E, Sidow D, et al. Is there a future for 74 Gy radiation treatment of NSCLC after RTOG 0617? A comparison of the RTOG study results with our own department's 74 Gy NSCLC cohort. J Cancer Ther 2015;6:642-7. 